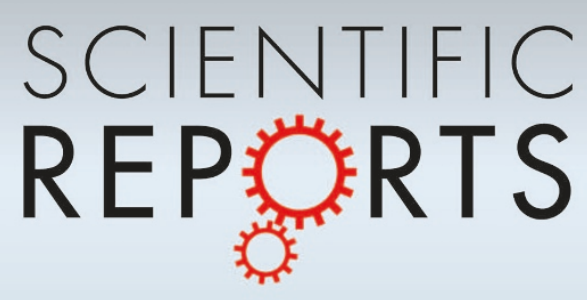

OPEN

SUBJECT AREAS:

CHRONIC

INFLAMMATION

INFLAMMATORY BOWEL DISEASE

Received

20 March 2014

Accepted

17 July 2014

Published

22 August 2014

Correspondence and requests for materials should be addressed to

Y.Q.L. (mx8902@

163.com)

\section{Gadolinium chloride improves the course of TNBS and DSS-induced colitis through protecting against colonic mucosal inflammation}

\author{
Chao Du' ${ }^{1,2}$, Peng Wang' ${ }^{1}$ Yanbo Yu' , Feixue Chen', Jun Liu' \& Yanqing Li' \\ 'Department of Gastroenterology, Qilu Hospital, Shandong University, Jinan, Shandong 250012, PR China, ${ }^{2}$ Department of
Gastroenterology, Linyi People's Hospital, Linyi, Shandong, 276000, PR China.
}

Inflammatory macrophages in colonic mucosa are the leading drivers of the pathology associated with inflammatory bowel disease (IBD). Here we examined whether gadolinium chloride $\left(\mathrm{GdCl}_{3}\right)$, a macrophage selective inhibitor, would improve the course of 2,4,6-trinitro benzene sulfonic acid (TNBS) and dextran sodium sulfate (DSS)-induced colitis in mice and the potential mechanisms were investigated. By giving $\mathrm{GdCl}_{3}$ to colitis mice through intravenous or intrarectal route, we found that $\mathrm{GdCl}_{3}$ markedly ameliorated the colitis severity, including less weight loss, decreased disease activity index scores, and improved mucosal damage. To investigate the potential mechanisms, flow-cytometric analysis was performed to detect the proportion of mucosal macrophages in colon. The results showed that $\mathrm{GdCl}_{3}$ had no macrophage depletion effect in colonic mucosa, but significantly suppressed TNBS and DSS-induced TNF $\alpha$, IL-1 $\beta$ and IL-6 secretions. Also, Western blotting analysis indicated that NF-кB p65 expression was significantly attenuated in the mucosa in colitis mice with $\mathrm{GdCl}_{3}$ treatment. Then, the anti-inflammatory activity of $\mathrm{GdCl}_{3}$ was confirmed in LPS-stimulated RAW 264.7 cells that $\mathrm{GdCl}_{3}$ might down-regulate the production of proinflammatory cytokines by macrophages through inhibition of the NF-кB signaling pathway. Therefore, intervention with mucosal inflammatory macrophages may be a promising therapeutic target in IBD.

nflammatory bowel disease (IBD) comprises Crohn's disease and ulcerative colitis that cause chronic and remittent-relapsing intestinal inflammation of all or part of the intestinal tract ${ }^{1,2}$. Although the aetiology of IBD remains unclear, it is thought to result from dysregulation of the mucosal immune responses to intestinal bacterial antigens in genetically predisposed individuals ${ }^{1,3}$. Currently, treatment options for IBD are mainly focused on suppressing mucosal immune responses, including the use of 5-aminosalicylic acid (5-ASA) agents, steroids, antimicrobials, and some immunomodulators ${ }^{4}$. However, although they are reasonably successful in many patients, still a great number cannot achieve remission, highlighting the need for novel therapeutic targets.

Infiltration and activation of macrophages in colon are central features of IBD, and inflammatory macrophages in mucosa are thought to play an essential role in the pathogenesis of $\mathrm{IBD}^{2,5-7}$. In IBD and experimental colitis, monocytes in blood are recruited to the mucosa and differentiate into activated macrophages that produce proinflammatory cytokines, such as tumor necrosis factor $\alpha$ (TNF $\alpha$ ), interleukin (IL)- 1 and IL- $6^{2,7,8}$. Activation of $\mathrm{NF}-\kappa \mathrm{B}$ is thought as a strong inducer of these proinflammatory cytokine expressions $\mathrm{s}^{9,10}$, and activated NF- $\kappa \mathrm{B}$ has been demonstrated in colonic macrophages of patients with IBD. Alteration in cytokine production by macrophages is one major component of the pathology of IBD. Therefore, strategies for targeting inflammatory mucosal macrophages may be important for developing new therapeutics. However, studies on intervention with mucosal macrophages in colon are really limited, which might mainly due to the limited intervention methods.

Gadolinium chloride $\left(\mathrm{GdCl}_{3}\right)$, a rare earth metal, is widely used experimentally ${ }^{11,12}$. The role of $\mathrm{GdCl}_{3}$ in macrophage elimination has been widely proven in liver of experimental animals, indicating a preventive or therapeutic effect in liver injury ${ }^{12-14}$. $\mathrm{GdCl}_{3}$ is also employed as a macrophage selective inhibitor in $v_{i v o^{11}}$. It has been reported that $\mathrm{GdCl}_{3}$ has no depletion effect in tissue macrophages in lung, but it decreases the expression of TNF $\alpha$ and IL-6 after LPS stimulation in rat $^{15}$. However, the effect of $\mathrm{GdCl}_{3}$ on mucosal macrophages in colon remains largely unknown. 

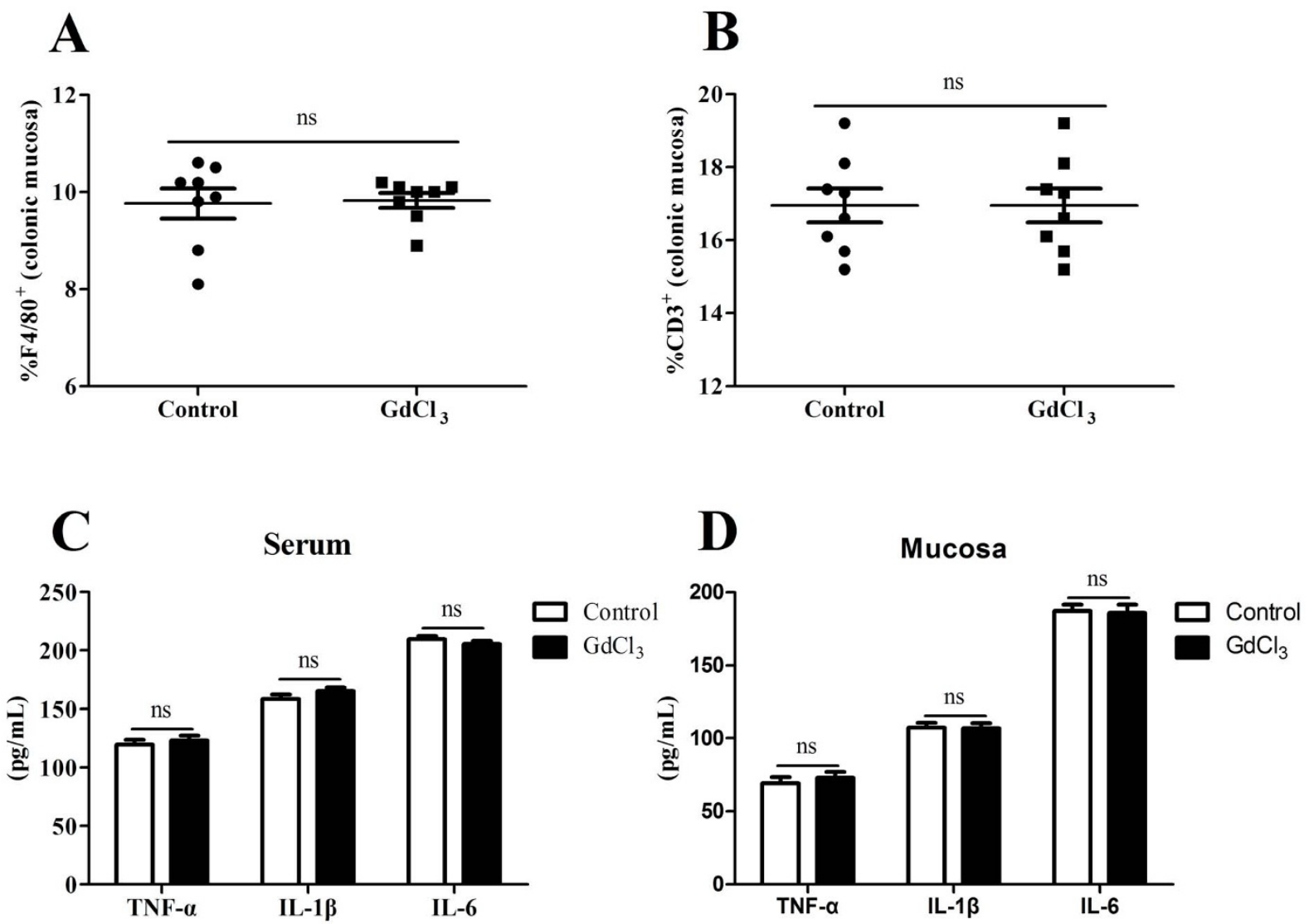

Figure $1 \mid \mathrm{GdCl}_{3}$ had no macrophage depletion effect in colonic mucosa. After intravenous treatment of $\mathrm{GdCl}_{3}(10 \mathrm{mg} / \mathrm{kg}$ body weight) for 1 day, mice were killed, and the proportion of mucosal macrophages in colon and the cytokine expression levels in serum and colonic mucosa were evaluated. (A) Proportion of mucosal macrophages in colon. (B) Proportion of $\mathrm{CD}^{+}$cells in colonic mucosa. (C) Cytokine expression of TNF $\alpha$, IL-1 $\beta$ and IL-6 in serum. (D) Cytokine levels of TNF $\alpha$, IL-1 $\beta$ and IL-6 in colonic mucosa. (ns: no significance).

Experimental animal models are crucial tools that provide a road map allowing us to probe the pathogenesis of diseases and to test emerging therapeutic strategies. 2,4,6-trinitro benzene sulfonic acid (TNBS) and dextran sodium sulfate (DSS) colitis models are canonical IBD models that the onset of inflammation is immediate and the procedure is relatively straightforward; therefore, the two models have been frequently used to evaluate the efficacy of potential therapeutic agents ${ }^{16,17}$.

The present study was performed to investigate the protective role and the potential mechanisms of $\mathrm{GdCl}_{3}$ in TNBS- and DSS-induced colitis. We studied the elimination effect of $\mathrm{GdCl}_{3}$ on mucosal macrophages. The colitis severity that included body weight loss, disease activity index scores, and mucosal damage, was evaluated, and the protein secretion of cytokines and the activity of NF- $\mathrm{KB}$ signal pathways were also studied in colitis mice treated with $\mathrm{GdCl}_{3}$. Also, the role of $\mathrm{GdCl}_{3}$ in macrophages was further investigated in activated RAW 264.7 cells in vitro.

\section{Results}

$\mathrm{GdCl}_{3}$ has no elimination effect on mucosal macrophages in colon in mice. The effect of $\mathrm{GdCl}_{3}$ on mucosal macrophages in colon is still unknown. In this study, we evaluated the proportion of mucosal macrophages in colon in mice after intravenous administration of $\mathrm{GdCl}_{3}$. It was revealed that intravenous treatment of $\mathrm{GdCl}_{3}$ at each concentration could not deplete macrophages in colonic mucosa. We then used $\mathrm{GdCl}_{3}$ at a concentration of $10 \mathrm{mg} / \mathrm{kg}$ body weight for 1 day before animal treatment for further study in accordance with the method described previously ${ }^{15,18}$.

Figure 1A showed that the proportion of macrophages in colonic mucosa was not altered after $\mathrm{GdCl}_{3}$ treatment $(10 \mathrm{mg} / \mathrm{kg}$ body weight) for 1 day in mice $(9.76 \pm 0.31 \%$ vs $9.83 \pm 0.15 \%, p>$ 0.05). No difference in the proportion of $\mathrm{CD}^{+}$cells in colonic mucosa was observed between $\mathrm{GdCl}_{3}$-treated mice and control mice $(p>0.05$; Figure 1B). In serum and colonic mucosa tissue, the expression profiles of TNF $\alpha$, IL-1 $\beta$ and IL- 6 were not obviously elevated after $\mathrm{GdCl}_{3}$ treatment $(p>0.05$ for all three cytokine types; Figures $1 \mathrm{C}, \mathrm{D})$. Thus, $\mathrm{GdCl}_{3}$ could not deplete macrophages in colonic mucosa and also would not induce inflammation in vivo.

$\mathrm{GdCl}_{3}$ is protective against colitis induced by TNBS and DSS. To evaluate the potential role of $\mathrm{GdCl}_{3}$ in colitis in vivo, we used two murine models of colitis induced by TNBS and DSS. In TNBS colitis, $\mathrm{GdCl}_{3}$ was given to mice on day 3 of TNBS application intravenously. The mortality of TNBS colitis mice was improved by about $20 \%$ after $\mathrm{GdCl}_{3}$ treatment (Figure 2A). Treatment with $\mathrm{GdCl}_{3}$ resulted in prominent protection from colitis as assessed by body weight, disease activity index (DAI) scores, colon length and histopathological damage of the colon. Control mice presented weight loss after TNBS administration, whilst colitis mice treated with $\mathrm{GdCl}_{3}$ showed markedly less body weight loss (Figure $2 \mathrm{~B}$ ). $\mathrm{GdCl}_{3}$ significantly improved DAI scores and shortening of colon length in TNBS colitis (Figures 2C, D). Histopathological analysis of the colon, examined on day 7 and 14, showed marked crypt architecture damage, inflammatory cell infiltration and ulceration in colitis mice. $\mathrm{GdCl}_{3}$ treatment significantly improved these damages of colon as assessed by the histopathological scores (Figure 2E).

Intrarectal treatment of $\mathrm{GdCl}_{3}$ began on day 3 of TNBS application and continued until day 7. Colitis was also significantly ameliorated after $\mathrm{GdCl}_{3}$ administration as assessed by changes of body weight, DAI scores, and mucosal damage, which were similar to mice 

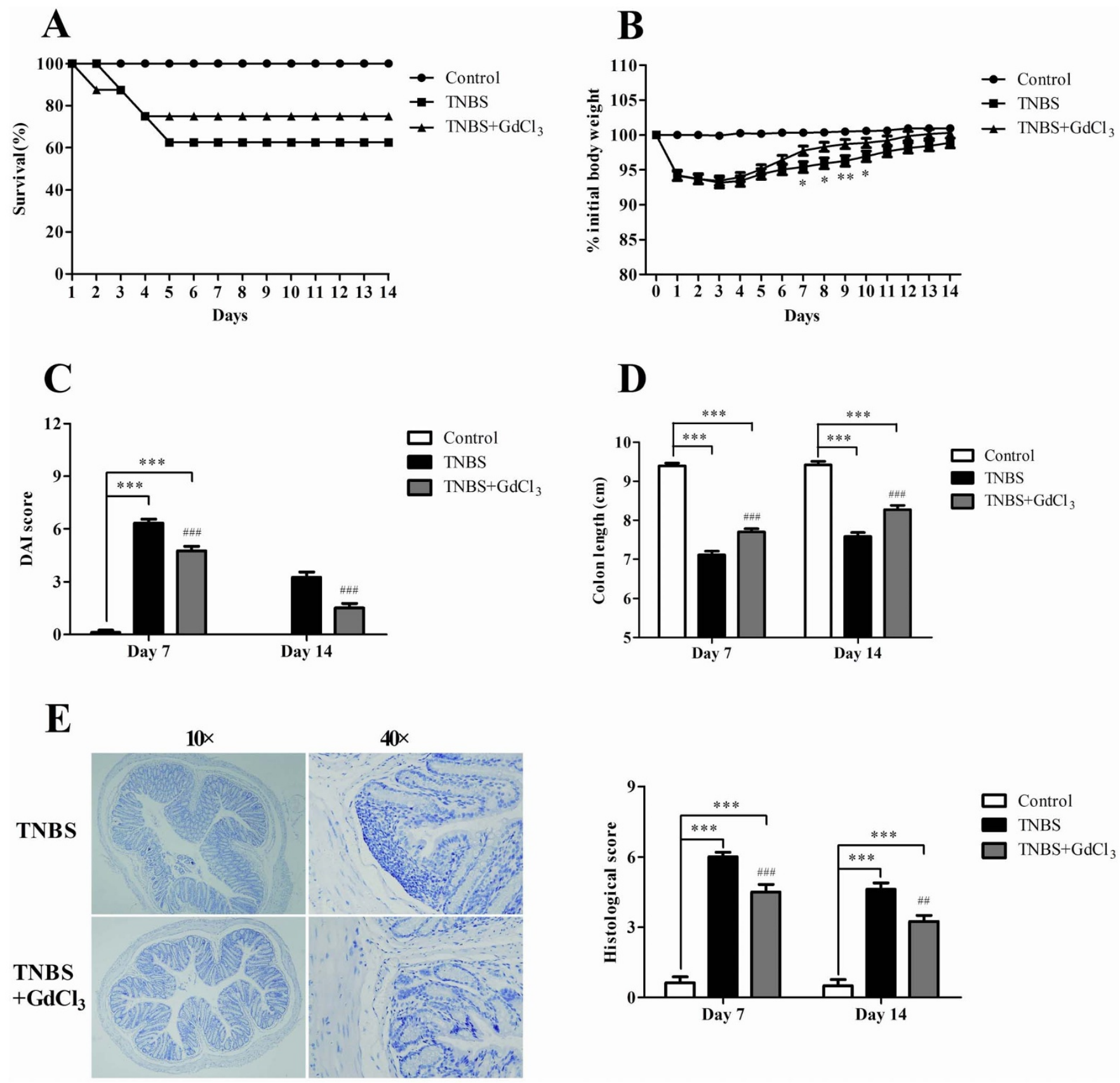

Figure $2 \mid \mathrm{GdCl}_{3}$ was protective against colitis in TNBS-treated mice. After induction of TNBS colitis, $\mathrm{GdCl}_{3}$ was given to mice intravenously on day 3 . After colitis induction for 7 days or 14 days, mice were killed, and the colitis severity was evaluated. (A) The survival rate. (B) The percentage of initial body weight. (C) The disease activity index (DAI). (D) The colon length. (E) The histopathological evaluation. $\left({ }^{*} P<0.05, * * P<0.01\right.$, ${ }^{* * *} P<0.001 ;{ }^{\# \#} P<0.01,{ }^{\# \#} P<0.001$ comparing TNBS $+\mathrm{GdCl}_{3}$ to TNBS).

treated with $\mathrm{GdCl}_{3}$ intravenously, and there was no significant difference between mice treated with $\mathrm{GdCl}_{3}$ through intravenous route and intrarectal route.

Mice were exposed to 3\% DSS in drinking water for 7 days in DSS colitis. $\mathrm{GdCl}_{3}$ was administrated to mice through either intravenous or intrarectal route similar to the treatment in TNBS colitis mice. The results revealed that $\mathrm{GdCl}_{3}$ treatment also resulted in striking protection from DSS-induced colitis (Table 1).

$\mathrm{GdCl}_{3}$ suppresses TNBS- and DSS-induced proinflammatory cytokine secretions. To evaluate whether the protection from colitis induced by TNBS and DSS in mice with $\mathrm{GdCl}_{3}$ treatment was associated with a reduction in the production of proinflammatory cytokines, expression levels of TNF $\alpha$, IL- $1 \beta$ and IL- 6 in serum and colonic mucosa of vehicle and mice treated with $\mathrm{GdCl}_{3}$ were detected using ELISA.

In TNBS colitis mice treated with $\mathrm{GdCl}_{3}$ intravenously, the proportion of macrophages and $\mathrm{CD}^{+}$cells in colonic mucosa was not altered on both day 7 and day 14 (Figures $3 \mathrm{~A}, \mathrm{~B}$ ). On day 7, TNF $\alpha$, IL$1 \beta$ and IL-6 protein levels were significantly increased in serum and colonic mucosa obtained from mice treated with TNBS (Figures 3C, D). On day 14 , expression profiles of TNF $\alpha$, IL- $1 \beta$ and IL- 6 were a little down-regulated (Figures $3 \mathrm{C}, \mathrm{D}$ ). But $\mathrm{GdCl}_{3}$ treatment significantly reduced TNF $\alpha$, IL-1 $\beta$ and IL- 6 levels in serum and colonic mucosa on day 7 as compared to those of vehicle control mice (Figures 3C, D). A significant suppression by $\mathrm{GdCl}_{3}$ treatment of TNF $\alpha$, IL- $1 \beta$ and IL- 6 levels in serum and colonic mucosa was also noted on day 14 (Figures 3C, D). 
Table $1 \mid$ The role of $\mathrm{GdCl}_{3}$ in DSS colitis mice

\begin{tabular}{|c|c|c|c|c|c|c|}
\hline & \multicolumn{2}{|c|}{ Control } & \multicolumn{2}{|c|}{ DSS } & \multicolumn{2}{|c|}{$\mathrm{DSS}+\mathrm{GdCl}_{3}$} \\
\hline Survival (\%) & 100 & 100 & 50 & 50 & 75 & 75 \\
\hline DAl score & $0.13 \pm 0.35$ & 0 & $6.88 \pm 1.26$ & $3.50 \pm 1.20$ & $5.25 \pm 1.04^{*}$ & $2.25 \pm 0.89 *$ \\
\hline Colon length & $9.40 \pm 0.20$ & $9.43 \pm 0.26$ & $6.85 \pm 0.28$ & $7.31 \pm 0.24$ & $7.19 \pm 0.24 *$ & $7.60 \pm 0.22 *$ \\
\hline Histological score & $0.63 \pm 0.74$ & $0.50 \pm 0.76$ & $6.13 \pm 0.99$ & $4.63 \pm 0.92$ & $4.50 \pm 0.93 * *$ & $2.88 \pm 0.83^{*}$ \\
\hline Serum IL-6 (pg/mL) & $206.3 \pm 4.55$ & $206.3 \pm 21.28$ & $522.1 \pm 60.97$ & $432.4 \pm 27.32$ & $384.0 \pm 45.58^{*}$ & $271.1 \pm 31.88^{* *}$ \\
\hline$\% \mathrm{~F} 4 / 80^{+}$cells in mucosa & $9.76 \pm 0.87$ & $9.75 \pm 0.68$ & $14.03 \pm 0.90$ & $12.93 \pm 1.15$ & $13.95 \pm 0.88$ & $12.87 \pm 1.13$ \\
\hline$\% \mathrm{CD}^{+}$cells in mucosa & $16.95 \pm 1.32$ & $16.89 \pm 1.21$ & $20.27 \pm 0.84$ & $18.47 \pm 1.39$ & $19.05 \pm 0.79$ & $17.36 \pm 1.31$ \\
\hline Mucosal TNF- $\alpha$ (pg/mL) & $72.3 \pm 13.94$ & $74.6 \pm 6.47$ & $562.2 \pm 19.76$ & $450.3 \pm 17.64$ & $366.0 \pm 8.74^{* * *}$ & $291.2 \pm 16.98^{* * *}$ \\
\hline Mucosal IL-1 $\beta$ (pg/mL) & $105.3 \pm 9.67$ & $106.6 \pm 17.75$ & $688.3 \pm 11.86$ & $364.2 \pm 22.94$ & $449.1 \pm 10.65^{* * *}$ & $364.2 \pm 22.94 * * *$ \\
\hline Mucosal IL-6 (pg/mL) & $191.2 \pm 14.90$ & $193.2 \pm 28.11$ & $730.3 \pm 33.70$ & $620.4 \pm 33.58$ & $593.1 \pm 28.62 * *$ & $505.3 \pm 33.50 *$ \\
\hline
\end{tabular}

$\mathrm{GdCl}_{3}(10 \mathrm{mg} / \mathrm{kg}$ body weight) was given to DSS colitis mice on day 3 after colitis induction through intravenous administration (DSS $+\mathrm{GdCl} 3)$, while PBS was given to the control DSS colitis mice (DSS). On day 7 or day 14 , mice were killed, and clinical symptoms, mucosal damage and colonic inflammation were evaluated. All data were expressed as mean values $S E M \pm S D$.

$* P<0.05$,

$* * P<0.01$,

$* * * P<0.001$ comparing DSS $+\mathrm{GdCl}_{3}$ to DSS

The proportion of mucosal macrophages and $\mathrm{CD}^{+}$cells in colon was also not changed in TNBS colitis mice treated with $\mathrm{GdCl}_{3}$ intrarectally. TNBS-induced expression levels of TNF $\alpha$, IL-1 $\beta$ and IL-6 were significantly decreased after intrarectal administration of $\mathrm{GdCl}_{3}$, which were not different from those in mice treated with $\mathrm{GdCl}_{3}$ intravenously.

In DSS colitis mice, $\mathrm{GdCl}_{3}$ was administrated to mice through either intravenous or intrarectal route. The results indicated that $\mathrm{GdCl}_{3}$ also showed an anti-inflammatory property in serum and colonic mucosa (Table 1).

$\mathrm{GdCl}_{3}$ reduces proinflammatory cytokine production by LPSstimulated RAW 264.7 cells. The anti-inflammatory activity of $\mathrm{GdCl}_{3}$ was also confirmed in LPS-stimulated RAW 264.7 cells in vitro. To define the experimental dose range of $\mathrm{GdCl}_{3}$ for in vitro use, its effect on cell viability was assessed by MTT assay. $\mathrm{GdCl}_{3}$ did not exert a toxicity in RAW 264.7 cells at a concentration ranging from 10 to $200 \mu \mathrm{M}$ (Figure $4 \mathrm{~A}$ ). Flow-cytometric analysis also showed a lack of pro-apoptotic effect of $\mathrm{GdCl}_{3}$ on the cell (data not shown). $\mathrm{GdCl}_{3}$ at a concentration of $100 \mu \mathrm{M}$ was used for further studies based on a previous study ${ }^{19}$. In RAW 264.7 cells, TNF $\alpha$, IL- $1 \beta$ and IL- 6 production was markedly increased in the culture supernatant after LPS stimulation, whereas the levels of these proinflammatory cytokines were significantly reduced by $\mathrm{GdCl}_{3}$ (Figures $4 \mathrm{C}, \mathrm{D}$ and $\mathrm{E}$ ).

$\mathrm{GdCl}_{3}$ suppresses NF- $\mathrm{B}$ activation in mucosa in colitis mice and also in LPS-stimulated RAW264.7 cells. Nuclear factor kappa B $(\mathrm{NF}-\kappa \mathrm{B})$, a transcription factor, plays an essential role in inflammation. Activation of macrophages is regulated by $\mathrm{NF}-\kappa \mathrm{B}$ activation $^{20}$. In TNBS colitis mice, the NF- $\kappa \mathrm{B}$ p65 expression in colonic mucosa was significantly attenuated with $\mathrm{GdCl}_{3}$ treatment through intravenous route on both day 7 and day 14 . (Figures $5 \mathrm{~A}$ and B) Intrarectal administration of $\mathrm{GdCl}_{3}$ also decreased the NF- $\kappa \mathrm{B}$ p 65 expression in colonic mucosa in TNBS colitis mice, which was similar to mice treated with $\mathrm{GdCl}_{3}$ intravenously. In DSS colitis mice, NF- $\kappa \mathrm{B}$ activation in mucosa was also suppressed with $\mathrm{GdCl}_{3}$ treatment. Also, in vitro studies showed that $\mathrm{GdCl}_{3}$ markedly reduced NF- $\kappa$ B p65 expression in LPS-stimulated RAW 264.7 cells (Figure $5 \mathrm{~B}$ ). Therefore, $\mathrm{GdCl}_{3}$ may down-regulate the secretion of proinflammatory cytokines by macrophages through suppression of $\mathrm{NF}-\kappa \mathrm{B}$ activation.

\section{Discussion}

IBD is a chronic inflammatory disease with rising incidence worldwide, and alteration in cytokine production by inflammatory macrophages is one major component. $\mathrm{GdCl}_{3}$ is a macrophage selective inhibitor, and has been proved to exert anti-inflammatory effect in lung and liver ${ }^{11,15}$. Here, for the first time, we showed a protection effect on colitis severity through an anti-inflammatory property of $\mathrm{GdCl}_{3}$ in colonic mucosa in vivo by suppressing the proinflammatory cytokine secretions by macrophages.

In this study, we demonstrated a protection against colitis induced by TNBS and DSS in mice with $\mathrm{GdCl}_{3}$ treatment, exhibiting improved weight loss, DAI scores, and mucosal damage. To investigate the protective mechanism of $\mathrm{GdCl}_{3}$ in colitis, we first evaluated whether $\mathrm{GdCl}_{3}$ had a macrophage eliminating role in mucosal macrophages in colon in mice. Previous studies had indicated that $\mathrm{GdCl}_{3}$ treatment efficiently depleted Kupffer cells in the liver ${ }^{11,21,22}$. Wehner, et al. ${ }^{23}$ had showed that intravenous treatment with chlodronate liposomes and $\mathrm{GdCl}_{3}$ led to a significant depletion of $52 \%$ muscularis macrophages in colon in rat. However, the result of our study showed an absence of macrophage depletion effect of $\mathrm{GdCl}_{3}$ in colonic mucosa in mice.

To evaluate whether the protection against colitis was associated with down-regulated production of proinflammatory cytokines, expression levels of TNF $\alpha$, IL- $1 \beta$ and IL- 6 in serum and colonic mucosa of vehicle and mice treated with $\mathrm{GdCl}_{3}$ were detected. Kono, et al. ${ }^{15}$ reported that $\mathrm{GdCl}_{3}$ had no depletion effect in tissue macrophages in lung, but it decreased the expression of TNF $\alpha$ and IL-6 in lung after LPS stimulation in rat. Results of our study revealed that the level of TNF $\alpha$, IL- $1 \beta$ and IL- 6 in colonic mucosa was markedly reduced in colitis mice with $\mathrm{GdCl}_{3}$ treatment. Thus, $\mathrm{GdCl}_{3}$ had an anti-inflammatory effect in colonic mucosa in colitis mice, possibly through suppressing the proinflammatory cytokine secretion by inflammatory macrophages.

It has been reported that the role of $\mathrm{GdCl}_{3}$ in lung injury might owe to the inhibition of production of inflammatory mediators by the Kupffer cells ${ }^{15}$. In our study, it was revealed that intravenous administration of $\mathrm{GdCl}_{3}$ induced remission in colitis mice. Thus it was possible that not only the reduced proinflammatory cytokine production by macrophages in mucosa but also the inhibition of production of inflammatory mediators by the Kupffer cells played a role in the remission of colitis. However, the present study revealed that $\mathrm{GdCl}_{3}$ treatment through intrarectal route showed a similar colitis-protective effect in colitis mice, and no significant difference 


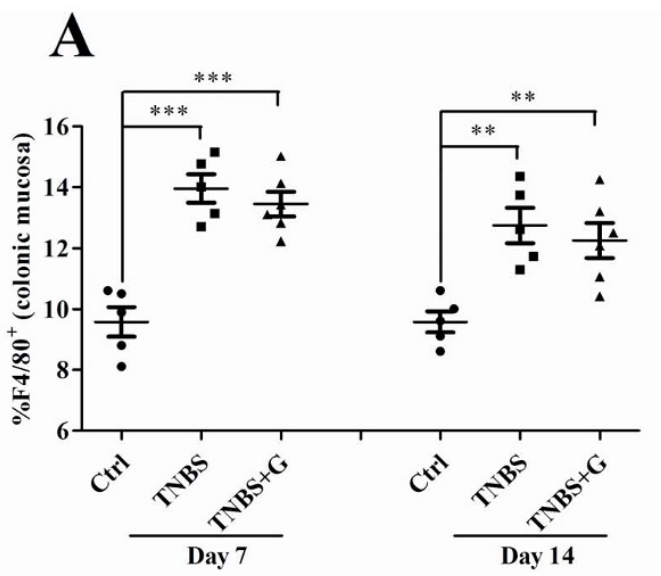

C

Day 7
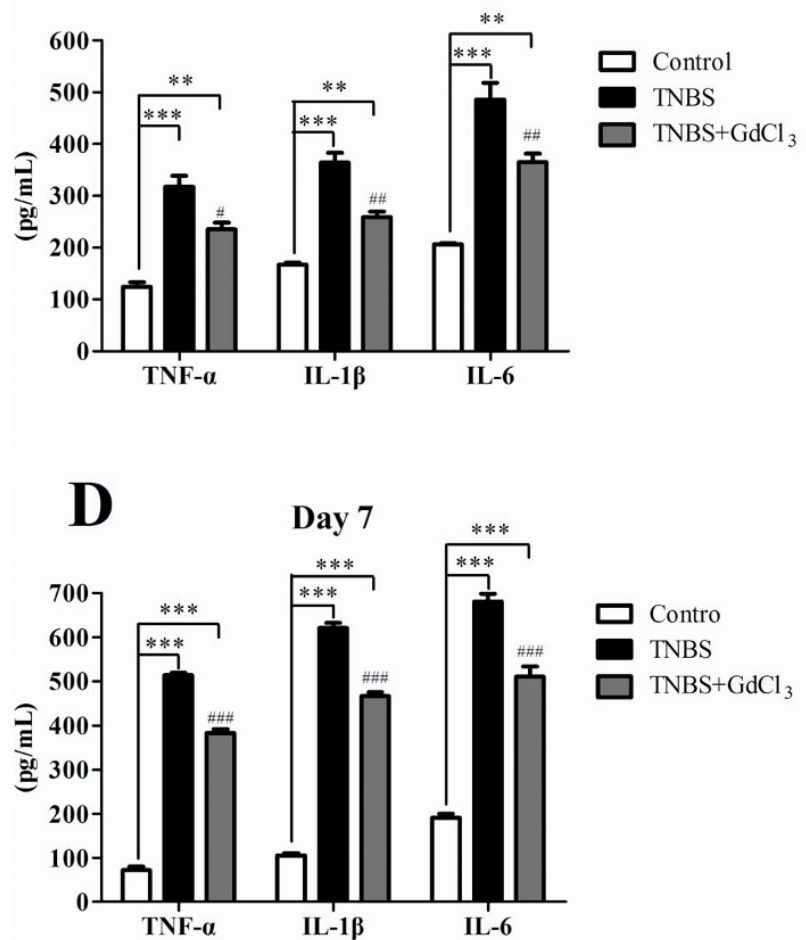
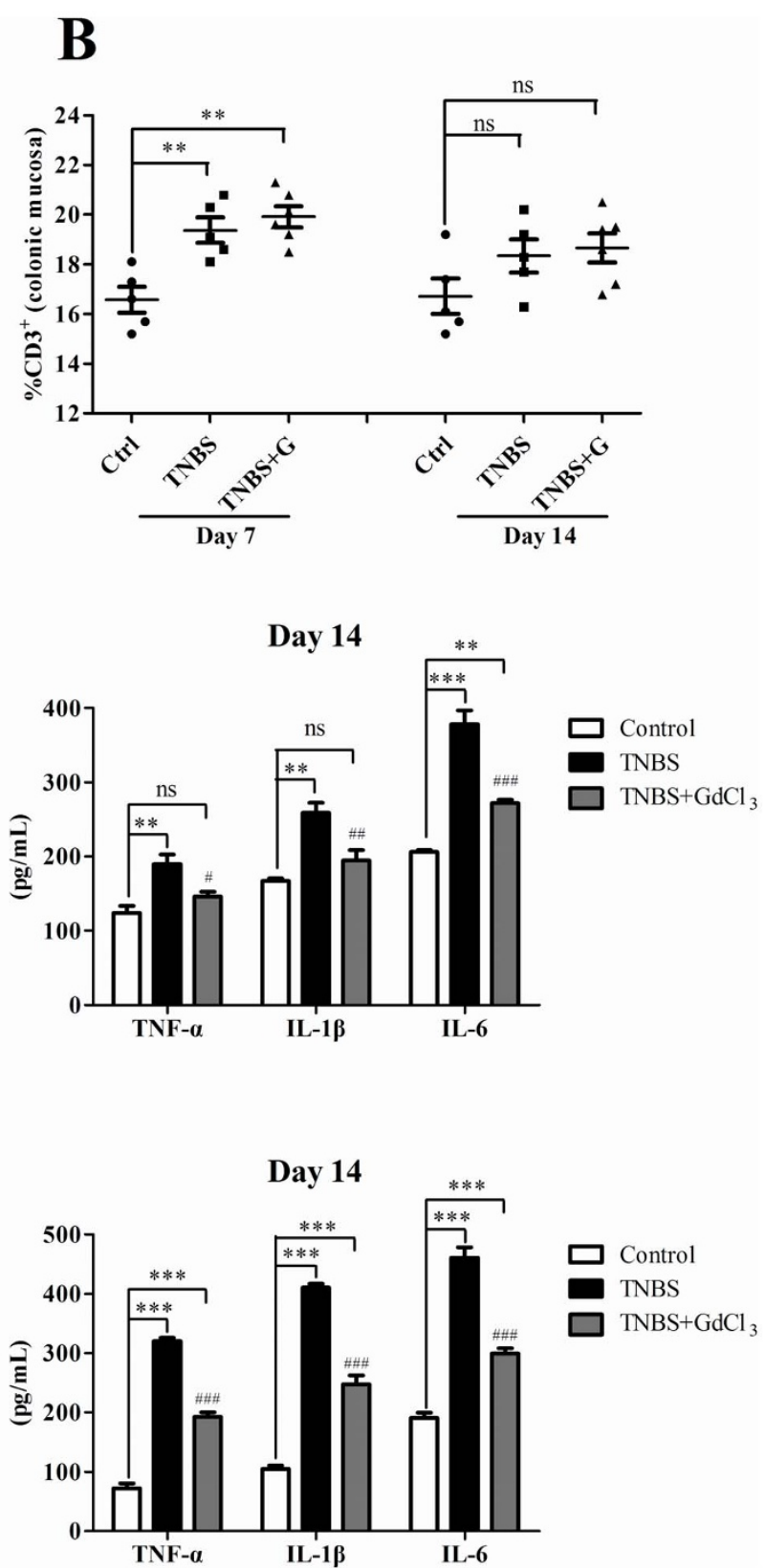

Figure $3 \mid \mathrm{GdCl}_{3}$ treatment reduced TNBS-induced TNFa, IL-1 $\boldsymbol{\beta}$ and IL-6 expressions. After induction of TNBS colitis, GdCl 3 was given to mice intravenously on day 3. And mice were killed on day 7 or day 14 . The amount of mucosal macrophages in colon and the levels of cytokines in serum and colonic mucosa were evaluated. (A) Proportion of mucosal macrophages in colon. (B) Proportion of mucosal CD3 ${ }^{+}$cells in colon. (C) Cytokine expression of TNF $\alpha$, IL-1 $\beta$ and IL-6 in serum. (D) Cytokine levels of TNF $\alpha$, IL-1 $\beta$ and IL-6 in colonic mucosa. (Ctrl, control; G, GdCl ${ }_{3}$ ) (ns: no significance; ${ }^{* *} P<0.01,{ }^{* * *} P<0.001 ;{ }^{*} P<0.05,{ }^{* *} P<0.01,{ }^{\# \# *} P<0.001$ comparing TNBS $+\mathrm{GdCl}_{3}$ to TNBS).

was found in colitis mice treated with $\mathrm{GdCl}_{3}$ through the two routes. These results further supported that $\mathrm{GdCl}_{3}$ induced remission in colitis mice through reducing proinflammatory cytokine production by inflammatory macrophages in colonic mucosa.

The anti-inflammatory property of $\mathrm{GdCl}_{3}$ was also confirmed in vitro in RAW 264.7 cells with LPS stimulation. Results of our study indicated that $\mathrm{GdCl}_{3}$ exerted no cytotoxic or pro-apoptotic effect in RAW264.7 cells, which is consistent with a previous report ${ }^{19}$. Production of TNF $\alpha$, IL-1 $\beta$ and IL- 6 was markedly reduced in the culture supernatant in LPS-stimulated cells with $\mathrm{GdCl}_{3}$ treatment. Therefore, $\mathrm{GdCl}_{3}$ also had an anti-inflammatory effect on activated macrophages in vitro, downregulating the production of proinflammatory cytokines.

Furthermore, western blot analysis showed that the expression of NF- $\kappa B$ p65 was significantly attenuated in colonic mucosa in colitis mice treated with $\mathrm{GdCl}_{3}$. In in vitro studies, $\mathrm{GdCl}_{3}$ also decreased NF- $\kappa \mathrm{B}$ p65 expression in activated RAW 264.7 cells. Thus, $\mathrm{GdCl}_{3}$ may improve the colitis severity through down-regulated secretion of proinflammatory cytokines in macrophages via inactivation of NF$\mathrm{B}$ signal pathway.

In summary, $\mathrm{GdCl}_{3}$ markedly improves the colitis severity in experimental colitis through suppression of NF- $\kappa \mathrm{B}$ activation with reduced production of proinflammatory cytokines by mucosal macrophages in colon. Therefore, it provides us a new and bright prospect of promising therapeutics in IBD.

\section{Methods}

Animal treatment. Male C57BL/6J mice weighing 20-25 g (aged 8-10 weeks) were used in this study. All mice were purchased from Beijing HFK Bioscience Company. 

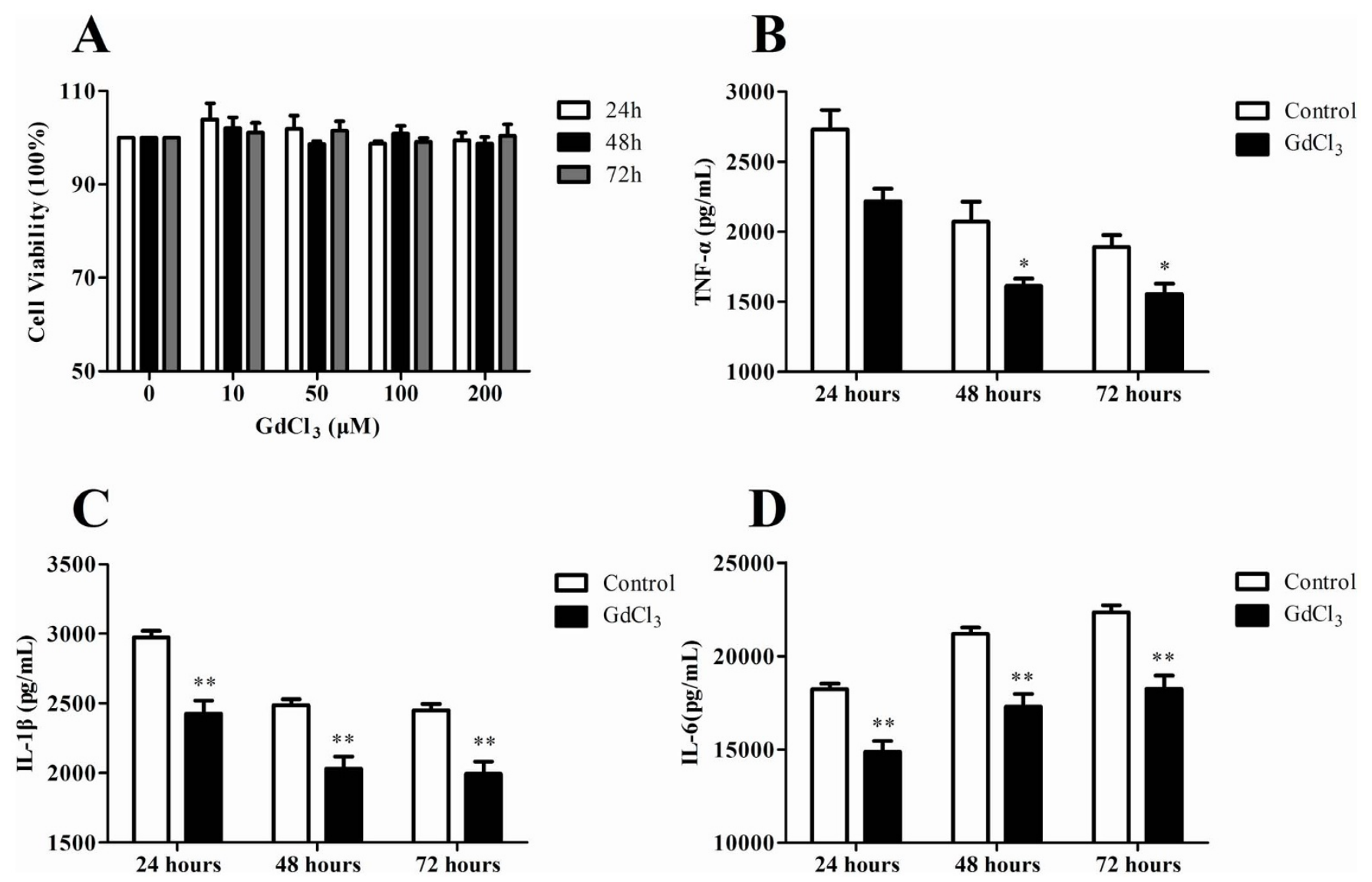

Figure $4 \mid \mathrm{GdCl}_{3}$ decreased proinflammatory cytokine production in LPS-stimulated RAW264.7 cells. RAW264.7 cells were treated with GdCl ${ }_{3}$ in various concentrations $(0-200 \mu \mathrm{M})$ for required incubation times to evaluate the cell viability. And then cells were stimulated with LPS (100 ng/mL) with or without $\mathrm{GdCl}_{3}(100 \mu \mathrm{M})$. At the end of incubation, the production of cytokines was determined. (A) Changes in cell viability. (B) Cytokine production of TNF $\alpha$. (C) Cytokine production of IL-1 $\beta$. (D) Cytokine production of IL-6. ( ${ }^{*} P<0.05$, $\left.{ }^{* *} P<0.01\right)$.

Animals were housed on a temperature- $\left(20 \pm 1^{\circ} \mathrm{C}\right)$ and light-controlled cycle (12 hours) with free access to standard laboratory chow and tap water. All procedures were approved by the Animal Care and Use Committee of Shandong University, and were performed in accordance with the Animal Management Rules of the Chinese Ministry of Health

$\mathrm{GdCl}_{3}(5,10,1520 \mathrm{mg} / \mathrm{kg}$ body weight; dissolved in $0.1 \mathrm{~mL} \mathrm{PBS}$ as a vehicle) was administrated to mice via the tail vein. The PBS vehicle $(0.1 \mathrm{~mL})$ was administrated as a control. Mice were sacrificed for detection of the amount of mucosal macrophages in colon after $\mathrm{GdCl}_{3}$ treatment for 1 day, 2 days and 3 days.

Colitis induction and design of treatment. Two well-established colitis models were used in this study. The TNBS colitis was induced by rectal administration of TNBS ( $2 \mathrm{mg}$ in $50 \%$ ethanol, $0.1 \mathrm{~mL}$ in total) (Sigma-Aldrich, St. Louis, MO) via a polyethylene catheter inserted 2 to $3 \mathrm{~cm}$ from the anus. An equivalent volume of PBS was instilled into control mice. The DSS colitis was induced by an intake of $3 \%(\mathrm{w} / \mathrm{v})$ DSS (40,000 MW) (MP Biomedicals, Solon, OH) dissolved in drinking water for 7 consecutive days, and then was replaced with regular water for another 7 days. Control mice received only drinking water. $\mathrm{GdCl}_{3}(10 \mathrm{mg} / \mathrm{kg}$ body weight) was given to mice on day 3 of TNBS and DSS application through intravenous route or begun on day 3 of TNBS and DSS application and continued until day 7 through intrarectal route. Control mice received equivalent administration of PBS. Mice were sacrificed on day 7 or day 14 after induction of colitis.

Evaluation of colitis progression. Body weights were recorded daily. Severity of colitis was assessed by the disease activity index (DAI) based on weight loss, stool bleeding and stool consistency in accordance with the method described previously ${ }^{24,25}$. The DAI was scored on a scale of $0-4$ for each parameter and then summed up for each mouse and each group.

Mice were killed on day 7 or day 14 with colons removed. Colons were measured and cut into sections. Histopathological studies were performed on paraffinembedded, $4 \mu \mathrm{m}$ thick distal colon sections, stained with haematoxylin and eosin. Histology was scored microscopically in a blinded fashion ${ }^{26,27}$ as shown in Table 2.

Flow cytometric analysis of mucosal macrophages in colon. Colons were dissected from euthanized mice, and the fecal contents and mesenteric tissues were removed. Under a Leitz dissection microscope, the colonic mucosa was gently peeled off the underlying layers, using a pair of fine dissection forceps. The mucosa were then cut into pieces of about $5 \mathrm{~mm}$, and placed into $10 \mathrm{mg} \cdot \mathrm{mL}^{-1}$ collagenase I in DMEM supplemented with $10 \% \mathrm{FBS}$ at $37^{\circ} \mathrm{C}$ for $60 \mathrm{~min}$. At the end of the reaction, the enzymatic action was blocked with $5 \mathrm{~mm}$ EDTA at $37^{\circ} \mathrm{C}$ for $10 \mathrm{~min}$. The suspension was filtered on nylon mesh $(70 \mu \mathrm{m})$, and cells were harvested after centrifugation for $5 \mathrm{~min}$ at $1000 \mathrm{~g}$ and resuspended in PBS. The cells were incubated for $20 \mathrm{~min}$ at $4{ }^{\circ} \mathrm{C}$ in the dark with the antibodies, and then were detected using a BD flow cytometer. The following antibody clones were used: F4/80-FITC, which had been used previously $^{24,28}$, and CD3-FITC from eBiosciense (San Diego, CA).

Measurement of cytokine levels in serum and colonic mucosa. After collection, peripheral blood was centrifuged for $5 \mathrm{~min}$ at $1500 \mathrm{~g}$, and serum was collected. Colonic mucosa was cut into pieces and was initially homogenised in a prepared icecold $100 \mathrm{~mm}$ Tris-HCl buffer, $\mathrm{pH} 7.0$, containing a cocktail of protease inhibitors (Beyotime, Shanghai, China) supplemented with $1 \mathrm{~mm}$ phenylmethanesulfonyl fluoride. Levels of TNF $\alpha$, IL-1 $\beta$ and IL-6 in serum and colonic mucosa were measured by ELISA kits (KYM, Beijing, China) according to the manufacture's recommendations.

Cell culture and treatment. RAW264.7 cells were cultured in Dulbecco's Modified Eagle's Medium (DMEM, Gibco by Invitrogen, CA, USA), containing 10\% fetal bovine serum (FBS, Gibco). Cells were seeded onto the 96-well plate with $5.0 \times 10^{3}$ cells per well. After 12 hours, cells were treated with gadolinium chloride $\left(\mathrm{GdCl}_{3}\right.$, Sigma-Aldrich, St. Louis, MO) in various concentrations $(0-200 \mu \mathrm{M})$ for required incubation times ( 24 hours, 48 hours and 72 hours).

Cell viabilities and apoptosis of $\mathrm{RAW} 264.7$ cells with $\mathrm{GdCl}_{3}$ treatment. At the end of incubation of $\mathrm{GdCl}_{3}$ in RAW264.7 cells, 3-[4, 5-dimethylthiazol-2-yl]-2, 5-

diphenyltetrazo-lium bromide (MTT, Amresco, Solon, OH, USA) in PBS was added to each well to reach a final concentration of $0.5 \mathrm{mg} / \mathrm{mL}$ and the cells were further incubated at $37^{\circ} \mathrm{C}$ for 4 hours. Then the supernatant was removed, and $150 \mu \mathrm{L}$ DMSO was added to dissolve the formazan. Absorbance was measured at $490 \mathrm{~nm}$ on a microplate reader (ThermoFisher Scientific, San Jose, CA). The viabilities of treated cells were expressed as the percentage of control cells, which was assumed to be $100 \%$.

After treatment with $\mathrm{GdCl}_{3}$ for 24 hours, RAW264.7 cells were trypsinized. The cell pellets were obtained after centrifugation at $1000 \mathrm{rpm}$ for $5 \mathrm{~min}$. Cells were 
TNBS

$\mathrm{TNBS}+\mathrm{GdCl}_{3}$

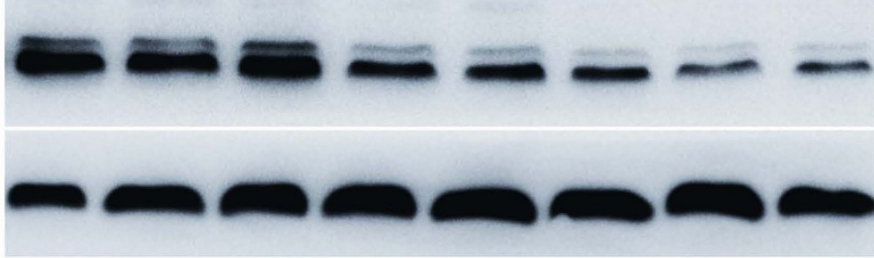

TNBS

$\mathrm{TNBS}+\mathrm{GdCl}_{3}$

Control

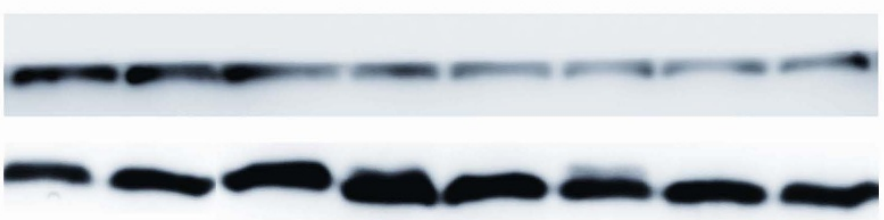

B
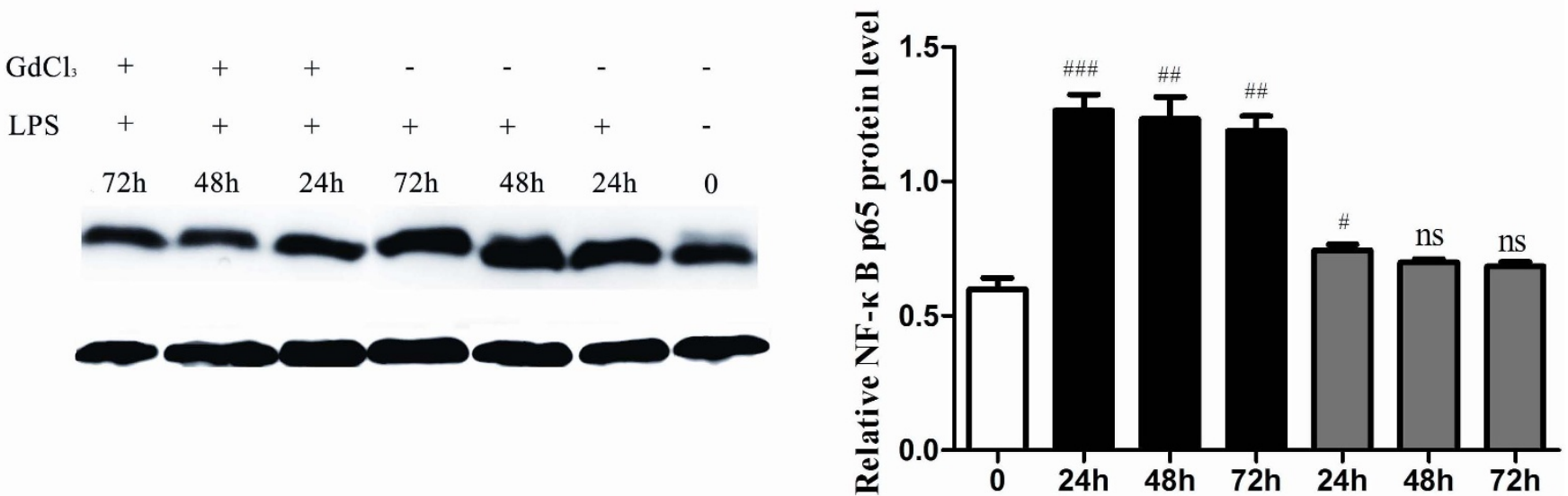

Figure $5 \mid \mathrm{GdCl}_{3}$ reduced NF- $\mathrm{KB}$ p65 expression in mucosa in colitis mice and also in LPS-stimulated RAW264.7 cells. (A) Western blot analysis

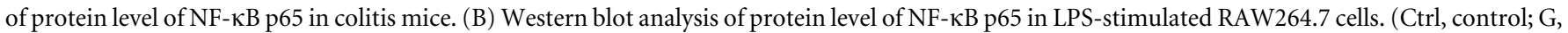
$\mathrm{GdCl}_{3}$ ) (ns: no significance; ${ }^{*} P<0.05,{ }^{* *} P<0.01$, ${ }^{* * *} P<0.01{ }^{*} P<0.05,{ }^{\# *} P<0.01,{ }^{\# \# *} P<0.001$ comparing TNBS $+\mathrm{GdCl}_{3}$ to TNBS in $(\mathrm{A})$; ${ }^{\# *} P<0.01$, ${ }^{\# \# \# P} P$. 001 comparing to the control in $\left.(\mathrm{B})\right)$.

washed twice with cold PBS and then were resuspended in $100 \mu \mathrm{L} 1 \times$ Binding buffer at a concentration of $1.0 \times 10^{6}$ cells $/ \mathrm{mL}$. Staining of FITC Annexin V and PI was according to the manufacture's instruction (FITC Annexin V apoptosis detection kit II, BD pharmingen ${ }^{\mathrm{TM}}$, San Diego, CA). The apoptotic rate was analyzed by flow cytometry.

LPS treatment and cytokine analysis. Cells $\left(3.0 \times 10^{4}\right)$ in $500 \mu \mathrm{L}$ medium were added to 24-well plates. After 12 hours, LPS at a concentration of $100 \mathrm{ng} / \mathrm{mL}$ with or without $\mathrm{GdCl}_{3}(100 \mu \mathrm{M})$ was added to the wells. The supernatants were collected

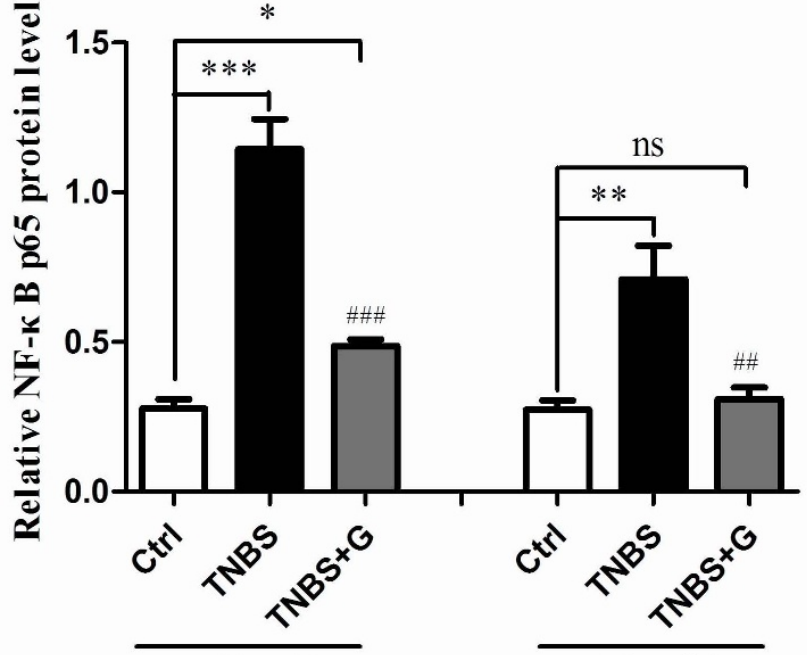

Day 14

24 hours, 48 hours and 72 hours after stimulation. The production levels of TNF $\alpha$ IL- $1 \beta$ and IL- 6 in the supernatant were detected by ELISA.

Western blot analysis. Total protein was extracted from mucosal samples of mice and from RAW 264.7 cell lysates in radioimmunoprecipitation assay (RIPA) buffer (Beyotime Institute of Biotechnology, Shanghai). Protein was quantified by using a BCA protein quantification kit (Beyotime). An amount of $20 \mu \mathrm{g}$ total protein from each sample was separated by sodium dodecyl sulfate-polyacrylamide gel electro phoresis and transferred to a polyvinylidene difluoride membrane $(0.22 \mu \mathrm{m}$ pore;

Table 2 | Grading of the histological evaluations

\begin{tabular}{llll} 
Scores & \multicolumn{1}{c}{ Crypt architecture } & \multicolumn{1}{c}{ Inflammatory cell infiltration } & \multicolumn{1}{c}{ Ulceration } \\
\hline 0 & normal & no infiltration & intact epithelium \\
1 & $<30 \%$ reduction of crypt length & infiltration of inflammatory cells in lamina propria & ulceration limited to lamina propria \\
2 & $>30 \%$ reduction of crypt length and loss of goblet cells & extending into the submucosa & extending to submucosa \\
3 & complete loss of crypts & transmural infiltration & transmural ulceration
\end{tabular}


Millipore, Bedford, MA, USA). After being blocked with 5\% skim milk powder diluted in TBS containing $0.1 \%$ Tween-20 for $1 \mathrm{~h}$, the membrane was incubated with primary antibodies (anti- NF- $\mathrm{KB}$ p65 monoclonal antibody, Santa Cruz Biotechnology, Santa Cruz, CA, USA) at $4^{\circ} \mathrm{C}$ overnight. Horseradish peroxidaseconjugated secondary antibodies (Zhongshan Gold Bridge, Beijing, China) were probed the next day, and an enhanced chemiluminescent substrate (Millipore) was used to detect the protein bands. Densitometry of protein bands was quantified by use of Quantity One 4.6.2 (Bio-Rad Laboratories, Hercules, CA, USA).

Statistical analysis. In mice, the nonparametric Mann-Whitney test was used to determine statistical differences between two groups. One-way ANOVA was performed to compare three groups. If the ANOVA analysis was significant, the Newman-Keuls test was applied for comparison between each two groups. In RAW264.7 cells, cytokine concentrations and NF- $\mathrm{kB}$ p 65 expressions were compared using the Student's t test. All data were analyzed with GraphPad Prism 5.01 (Graphpad Software, San Diego, CA, USA). Differences were considered statistically significant at $P<0.05$

1. Podolsky, D. K. Inflammatory bowel disease. N Engl J Med Vol. 347, 417-429 (2002)

2. Maloy, K. J. \& Powrie, F. Intestinal homeostasis and its breakdown in inflammatory bowel disease. Nature 474, 298-306 (2011).

3. Xavier, R. J. \& Podolsky, D. K. Unravelling the pathogenesis of inflammatory bowel disease. Nature 448, 427-434 (2007).

4. Baumgart, D. C. \& Sandborn, W. J. Inflammatory bowel disease: clinical aspects and established and evolving therapies. Lancet 369, 1641-1657 (2007).

5. Zhang, S., Liu, X., Wang, H., Peng, J. \& Wong, K. K. Silver nanoparticle-coated suture effectively reduces inflammation and improves mechanical strength at intestinal anastomosis in mice. J Pediatr Surg 49, 606-613 (2014).

6. Bain, C. C. \& Mowat, A. M. Intestinal macrophages - specialised adaptation to a unique environment. Eur J Immunol 41, 2494-2498 (2011).

7. Bain, C. C. et al. Resident and pro-inflammatory macrophages in the colon represent alternative context-dependent fates of the same Ly6C(hi) monocyte precursors. Mucosal Immunol 6, 498-510 (2012).

8. Zhang, Y. et al. Berberine Hydrochloride Prevents Post-Surgery Intestinal Adhesion and Inflammation in Rats. J Pharmacol Exp Ther 349, 417-426 (2014).

9. Andresen, L. et al. Activation of nuclear factor kappaB in colonic mucosa from patients with collagenous and ulcerative colitis. Gut 54, 503-509 (2005).

10. Schreiber, S. The complicated path to true causes of disease: role of nuclear factor kappaB in inflammatory bowel disease. Gut 54, 444-445 (2005).

11. Adding, L. C., Bannenberg, G. L. \& Gustafsson, L. E. Basic experimental studies and clinical aspects of gadolinium salts and chelates. Cardiovasc Drug Rev 19, 41-56 (2001).

12. Jiang, S., Gavrikova, T. A., Sharifov, O. F. \& Messina, J. L. Role of tissue macrophages in the development of critical illness diabetes. Shock 37, 70-76 (2012)

13. Hildebrand, F. et al. Kupffer cells and their mediators: the culprits in producing distant organ damage after trauma-hemorrhage. Am J Pathol 169, 784-794 (2006).

14. Montosi, G. et al. Kupffer cells and macrophages are not required for hepatic hepcidin activation during iron overload. Hepatology 41, 545-552 (2005).

15. Kono, H. et al. Role of Kupffer cells in lung injury in rats administered endotoxin 1. J Surg Res 129, 176-189 (2005)

16. Strober, W., Fuss, I. J. \& Blumberg, R. S. The immunology of mucosal models of inflammation. Annu Rev Immunol 20, 495-549 (2002).

17. Wirtz, S., Neufert, C., Weigmann, B. \& Neurath, M. F. Chemically induced mouse models of intestinal inflammation. Nat Protoc 2, 541-546 (2007).

18. Gill, S. S. et al. Role of pulmonary intravascular macrophages in endotoxininduced lung inflammation and mortality in a rat model. Respir Res 9, 69 (2008).
19. Gou, B. D., Bian, S., Zhang, T. L. \& Wang, K. Gadolinium-promoted precipitation of calcium phosphate is associated with profibrotic activation of RAW 264.7 macrophages. Toxicol In Vitro 24, 1743-1749 (2010).

20. Rogler, G. et al. Nuclear factor kappaB is activated in macrophages and epithelial cells of inflamed intestinal mucosa. Gastroenterology 115, 357-369 (1998).

21. Hardonk, M. J., Dijkhuis, F. W., Hulstaert, C. E. \& Koudstaal, J. Heterogeneity of rat liver and spleen macrophages in gadolinium chloride-induced elimination and repopulation. J Leukoc Biol 52, 296-302 (1992).

22. Ardelean, D. S. et al. Anti-VEGF therapy reduces intestinal inflammation in Endoglin heterozygous mice subjected to experimental colitis. Angiogenesis 17, 641-659 (2014).

23. Su, X. L. et al. [Shen warming Pi strengthening method intervened IBS-D rats: an efficacy assessment]. Zhongguo Zhong Xi Yi Jie He Za Zhi 34, 197-202 (2014).

24. Funakoshi, T. et al. A novel NF-kappaB inhibitor, dehydroxymethylepoxyquinomicin, ameliorates inflammatory colonic injury in mice. J Crohns Colitis 6, 215-225 (2012).

25. Qualls, J. E., Kaplan, A. M., van Rooijen, N. \& Cohen, D. A. Suppression of experimental colitis by intestinal mononuclear phagocytes. J Leukoc Biol 80, 802-815 (2006).

26. Hughes, P. A. et al. Post-inflammatory colonic afferent sensitisation: different subtypes, different pathways and different time courses. Gut 58, 1333-1341 (2009).

27. Reinecke, K. et al. The JNK inhibitor XG-102 protects against TNBS-induced colitis. PLoS One 7, e30985 (2012).

28. Heidemann, J., Kebschull, M., Tepasse, P. R. \& Bettenworth, D. Regulated expression of leukocyte-specific transcript (LST) 1 in human intestinal inflammation. Inflamm Res 63, 513-517 (2014).

\section{Acknowledgments}

The authors appreciate the considerable assistance from the Key Laboratory of Cardiovascular Remodeling and Function Research in the Qilu Hospital of Shandong University. This work was supported by the National Natural Science Foundation of China (81270457 and 81170352) and the scientific research foundation for outstanding young scientist of Shandong Province (BS2012SW012).

\section{Author contributions}

C.D. performed the experiments, analyzed the data and wrote the paper. P.W., Y.B.Y. F.X.C. and J.L. performed the experiments and analyzed the data. Y.Q.L. provided advice in designing experiments and writing the paper. All authors have reviewed the manuscript.

\section{Additional information}

Competing financial interests: The authors declare no competing financial interests.

How to cite this article: Du, C. et al. Gadolinium chloride improves the course of TNBS and DSS-induced colitis through protecting against colonic mucosal inflammation. Sci. Rep. 4, 6096; DOI:10.1038/srep06096 (2014)

This work is licensed under a Creative Commons Attribution-NonCommercialShareAlike 4.0 International License. The images or other third party material in this article are included in the article's Creative Commons license, unless indicated otherwise in the credit line; if the material is not included under the Creative Commons license, users will need to obtain permission from the license holder in order to reproduce the material. To view a copy of this license, visit http:// creativecommons.org/licenses/by-nc-sa/4.0/ 